\title{
Racial Inequity in Federal Grant Funding
}

\author{
Michael A. Taffe, Ph.D. ${ }^{1}$, Nicholas W. Gilpin, Ph.D. ${ }^{2,3,4}$
}

${ }^{1}$ Department of Psychiatry, University of California, San Diego, La Jolla CA 92093, USA.

${ }^{2}$ Department of Physiology, School of Medicine, Louisiana State University Health Sciences Center, New Orleans, LA 70112, USA.

${ }^{3}$ Neuroscience Center of Excellence, Louisiana State University Health Sciences Center, New Orleans, LA 70112, USA.

${ }^{4}$ Alcohol \& Drug Abuse Center of Excellence, Louisiana State University Health Sciences Center, New Orleans, LA 70112, USA.

*Co-corresponding author contacts: mtaffe@health.ucsd.edu and ngilpi@Isuhsc.edu

\section{Abstract}

Circulation of videos showing the death of George Floyd, at the hands of police officers, in May of 2020 prompted renewed national conversations about systemic racism. Biomedical research in the USA, including that supported by the National Institutes of Health (NIH), is not immune to the systemic racism that pervades American society. A groundbreaking analysis of NIH grant success revealed in 2011 that applications submitted by Black or African-American Principal Investigators (PIs) were less likely to be funded, compared with those submitted by white PIs. NIH efforts to respond have included attempts to attribute the effect to mediating variables other than PI race; attempts to fix the "pipeline" by funding more African-American trainees; and attempts to eliminate subconscious, or implicit, bias in peer reviewers. An updated report published in 2019 showed that nothing has changed and that topics of interest to African-Americans are less likely to be funded, even with white PIs. Here, we review the response of the NIH to these issues, which we argue are inadequate, and we issue a call to action for all participants in the tax-payer funded NIH system of research funding. It is unacceptable that $\mathrm{NIH}$ grant funding disparities based on the race of the PI continue to persist in the current system. It is unacceptable that health conditions and topics of interest to Black citizens are systematically overlooked for research funding. The NIH must create an actionable plan that permanently eliminates racial disparities in grant award.

\section{Introduction}

On May $25^{\text {th }}, 2020$, video clips circulated on the internet showing the death of George Floyd, caused by police officer Derek Chauvin kneeling on his neck for 8 minutes and 46 seconds (Hill et al., 2020). This event sparked protests across the US that continue to this day, and kickstarted numerous discussions about systemic racism in the USA. Among these conversations, many industries, professions and workplaces have reflected on the fact that they are built within, by and on a white supremacist culture, which has the effect of assisting white citizens in achieving success, while making it more difficult for Black citizens to do the same.
Indeed, any playing field that increases the chances of success for one group of people almost necessarily decreases the chances of success for another group of people. The discussions we are having in 2020 are making it clearer to all that white supremacist structures permeate nearly every aspect of American society. The vast enterprise of biomedical research science in the USA, and in particular the academic research that is supported by grant funding from the National Institutes of Health $(\mathrm{NIH})$, is no different. In fact, the $\mathrm{NIH}$ has been aware of racial disparities in the federal grant award system for over nine years. These racial disparities, which have gone unaddressed, are 
reflective of a federal grant system that is systemically racist.

In August 2011, a groundbreaking review of grant award success at NIH during fiscal years (FY) 2000-2006, as funded through its 24 Institutes and Centers (ICs) with funding authority, revealed that the probability of funding for research grant proposals submitted by African-American/Black Principal Investigators (PIs) was 13 percentage points lower than applications submitted by white PIs (Ginther et al., 2011). This was met with some consternation and an immediate denial that peer review could possibly be "racist." The NIH Director, Francis Collins, M.D., was quoted as saying "The situation is not acceptable...this is not just a problem for the NIH but the whole research community" (Corbyn, 2011). A follow-up study published in October 2019 showed that nothing had changed and applications with white PIs were still 1.7 times more likely to be funded than applications with Black PIs (Hoppe et al., 2019). In response to this, the NIH's Chief Officer for Scientific Workforce Diversity suggested only that they need "further study" to "explore the causal factors behind the R01 funding gap" (NIH, 2019). Nearly a decade after the initial report on grant funding disparity, it is unacceptable that NIH has not acted more directly and forcefully to redress the problem and, indeed, that nothing has changed.

\section{A Call to Action}

This editorial is a call to action for all of those involved in the academic biomedical research enterprise, especially for those that set policy at government (e.g., NIH program and grant review officers) and university (e.g., deans and chairs, promotion and tenure committee members) levels, those with tenure or other forms of job protection, those with a seat at the table where decisions are made (e.g., search and review committee members), those with a role in deciding who fills those chairs when they are vacated by past members (e.g., committee chairs), and those who are white or white-passing (and may have access to public or private conversations on these topics that more visually obvious people of color may not). It is time to move the burden of this fight from those most affected by it to those unaffected by it, from those exhausted by it to those that have had the luxury of ignoring it until now, and from junior scientists working to get a foothold in our field to senior scientists that already have one (Dzirasa, 2020; Odekunle, 2020).
This action can take many forms, but at the most fundamental level, all of these actions require one to actually... act; not to think about acting or talk about acting. As noted recently by Professor Carl Hart in this context: "Verbal behavior is not actual behavior" (Hart, 2020). Effective action first requires an admission by individuals and institutions regarding their respective roles in the systemic racism that created this situation - without this simple acknowledgment, it will be very difficult or impossible for scientists to believe the rhetoric about "doing better." Action also requires self-education, and self-education requires time and effort. Action without self-education may be more harmful than helpful, despite the best of intentions. Self-education on this topic will never end; it requires constant introspection and self-assessment by individuals and institutions, constant commitment to do better, and constant checking of one's own implicit and explicit biases. In a similar way, action also will never end; it requires constant vigilance for unlevel playing fields, threats to racial equity, willingness to call out colleagues and policies that fall short, and work to develop solutions that address these issues.

At this point, readers may be asking "What can I do to change a system that has existed for 400 years?" We do not claim to have all the answers, but we are confident in stating that systemic change comes from the decisions and actions of individuals and the journey of a thousand miles begins with but a single step. Find like-minded colleagues, discuss these issues rather than shy away from them, incentivize and value efforts related to these causes, and elevate and provide platforms for the voices speaking out on these topics.

\section{This Editorial has Two Goals}

First, we aim to educate everyone involved in the federal granting systems (e.g., program officials, administrators of, and participants in, peer review, the current and future generations of academic biomedical scientists at-large) on the racial disparities that exist in this system. NIH grant award is an integral component of career success for academic biomedical scientists, and it is imperative that there is a broad understanding of the racial disparities that exist in federal grant funding, the negative impact this award disparity has for Black grant applicants and for the field at-large, and it is critical that this understanding be used to guide policy. Second, we demand that the NIH immediately, effectively and permanently address 
racial inequities in federal grant funding rates, and we provide possible avenues for doing so.

To address these goals, we first outline the importance of the NIH grant award for the careers of biomedical scientists in the US, we then review the data illustrating the racial disparity in the federal granting system. We then address what the $\mathrm{NIH}$ is, and is not, doing in response to this disparity, and finally we suggest several steps they should, and should not, take. It is our hope that these final points regarding possible ways forward will educate and empower all stakeholders to demand significant and immediate action from the tax-payer funded $\mathrm{NIH}$. Any decisions to address this issue will have to come from the $\mathrm{NIH}$, and to this end it is critical that participants in this system (i.e., all biomedical research scientists) be educated on these racial disparities and engage the NIH (and each other) on these issues.

\section{Academic career currency}

In academic science, research grants are essential career currency, particularly in the most research-intensive universities. Grants are almost universally regarded as the most important factor in considerations of tenure and promotion at research institutions - while perceived deficits in teaching and service can often be excused away, deficits in research productivity rarely are. In most cases within biomedical disciplines, this research productivity (the publication of primary research articles) depends on grant funding. Grants fund the research which leads to publications and prestige, thereby making it easier for a professor to recruit students and post-doctoral fellows into the lab. These trainees then generate more research, which leads to more papers and more prestige in a feed-forward loop. Publications are an essential evaluative criterion in deciding who is hired into a new Assistant Professor position, who is promoted to Associate Professor and Full Professor, and who receives tenure. Beyond the role of grants in scientific productivity and career advancement, there are various levels of formal and informal expectations that a university professor, particularly in medical school departments, maintain robust funding in support of some fraction (oftentimes a large fraction) of their own salary. It therefore follows that inequities in the award of NIH grant funding have real and lasting consequences for the success of academic scientists. If we are to address disparities of opportunity for African-American/Black scientists in academic biomedical sciences research, it is essential to address disparities in funding rates.
The major source of research grant funding in the US, and by far the most highly regarded source of funding in biomedical disciplines, is the federal government of the United States. Of these federal grant awards, the most highly sought-after mechanism at medical schools is the R01 research grant from the National Institutes of Health. The R01 is considered by most to be the gold standard of federal grant funding, so much so that other large grants are often referred to as "R01-equivalent" grants in departmental or university criteria. Promotion and tenure criteria frequently mention "R01 or equivalent" as evidence of major extramural funding. That said, the discussion below is not limited to the R01 mechanism, although much of the data discussed were collected regarding R01 grants. In all likelihood, these trends extend, at least to some degree, to other individual research awards, center/program projects and training fellowships. For example, Black postdoctoral trainees who apply for the K99/R00 Pathway to Independence award are at a significant disadvantage relative to their white peers (Pickett, 2018).

One can imagine many reasons that people experience different rates of success in acquiring grant funding. Among these are quality of the grant application, prior achievements of the applicant, mentoring received or not received in early career stages, infrastructure to support grant writing, protected time for submitting grants, prestige of institution, the breadth and quality of the network with other scientists, topic choice and specific strategy for seeking funding. One can also imagine how many of these factors are intertwined: for example, strong mentoring received during early career stages will likely lead to higher productivity, more awards, perhaps a job at a more prestigious institution, and a more promising strategic approach to grant applications. It is also likely that early grant success leads to later grant success, or put more simply, that having funding leads to getting more funding. In colloquial terms, the rich get richer. Inevitably, on the other side of that coin, people that do not experience early career success face an uphill battle in achieving success later.

\section{Trickle down effects of racial inequities in funding}

There are many negative effects of racial disparities in federal grant scores and federal grant funding rates for the individual Black scientist, and these effects start early. As previously referenced, 
the likelihood of being awarded a grant intended to assist late-stage postdoctoral scientists progress to independence in an Assistant Professor is negatively affected (Pickett, 2018). In some cases, universities do not allow the hiring of new faculty members that do not bring federal grant dollars, and in many other cases, prior success in receiving federal grant funding gives job applicants a large advantage over those without such evidence of funding. As mentioned above, the granting of tenure to an Assistant Professor can be delayed or denied if the individual does not have major research funding - oftentimes this means an R01. Promotion to Full Professor frequently hinges on having won multiple or many R01 awards in series and/or concurrently. Aside from career advancement, prior success in acquiring federal research funding is tied to countless other dimensions of biomedical research careers.

Based on this, we can conclude that, if fewer grants are awarded to Black scientists this means that fewer Black colleagues will be able to establish and maintain vibrant research independence. This single phenomenon reduces racial equity and representation in each University and in each academic field. More insidiously, this has a vicious cyclical effect on future disparities and inequities. The overall effect of grant award disparities to reduce the actual number of Black scientists may be invisible to a person that is not looking for them, because they are "the absence of something" rather than "the presence of something." This makes it more probable that our institutions will fall for the pipeline fallacy, i.e., of thinking that the dearth of Black biomedical science professors is due to a lack of candidates for these jobs, rather than due to the difficulties they face in trying to gain and succeed in those jobs. This misconception can and does lead to suboptimal "pipeline" solutions that bring new junior scientists into an unchanged system, where they face the same old difficulties sustaining or thriving in their careers.

Lower funding rates for grants submitted by Black applicants leads directly to fewer Black scientists achieving true research independence, fewer securing tenure-track faculty positions, fewer maintaining continuity in their specific lab research projects and fewer who manage to obtain tenure. Fewer Black scientists in faculty positions and tenured positions at universities may, and probably does, lead to:
1. less attention focused on diversity and equity in recruitment and promotion, as well as other issues that disproportionately affect Black and other minorities

2. fewer Black scientists in leadership positions in science: for example, journal editors, society presidents, department chairs, and university administration

3. less recruitment of Black students into science, which may in itself be owed to several causes, including but not limited to less effort to achieve this by white faculty (i.e., targeted outreach), less exposure of the next generation of Black students to academic science (accelerated by the fact that Black students may be less able to perform unpaid, i.e., volunteer, work to gain experience, fewer role models in the field for Black students to emulate and/or fewer graduate program applications from Black students

4. less promotion of Black scientists (e.g., see Ginther 2011 Figure S9 on prior NRSA for Black R01 applicants)

5. less sensitivity to issues faced by Black trainees in science and less commitment to mentoring young Black scientists to independence

All of this leads to the inevitable conclusion that eliminating the disparity of $\mathrm{NIH}$ grant award rates for Black scientists is a critical and pressing issue that, if addressed, will have a large and long-term positive impact on providing equitable access to academic science careers, regardless of race. Furthermore, it is necessary that the taxpayer-funded science that is conducted with $\mathrm{NIH}$ grant dollars address the interests and health needs of US citizens of all races and ethnicitiew.

\section{Racial inequities in NIH grant funding}

As outlined above, several analyses of $\mathrm{NIH}$ funding trends have revealed that AfricanAmerican/Black scientists are less likely to receive $\mathrm{NIH}$ grant funding compared with their White, Hispanic/Latinx, or Asian colleagues. In the first study published Ginther and colleagues (Ginther et al., 2011) funding success rates were analyzed by the race of Principal Investigators (PIs) on R01 applications submitted for possible funding between Fiscal Year (FY) 2000 and FY2006 and included only Type 1 (new project) grants. (Although technically an applicant institution, such as a University, submits each grant application to the 
$\mathrm{NIH}$, in practice the $\mathrm{PI}$ is usually the major figure creating the proposal, often in collaboration with other colleagues.) The primary finding of Ginther et al. (Ginther et al., 2011) was that grants submitted with African-American/Black PIs (which were 1.4\% of the total sample) were funded at a probability of $17.1 \%$, whereas applications with white PIs (69.9\% of the total sample) were funded at a rate of $29.3 \%$ (see Table S2; Ginther et al., 2011). This represented a 1.7-fold advantage, in terms of likelihood to be funded, for the applications submitted with white PIs over those submitted with African-American/Black PIs.

Since publication of that landmark study, efforts by the NIH to respond to this finding fall into three categories: first, attempts to explain away the disparity by attributing this effect to mediating variables other than $\mathrm{PI}$ race; second, attempts to fix the "pipeline" by funding more AfricanAmerican/Black trainees at the predoctoral and postdoctoral career stages; and third, attempts to identify and eliminate bias at the level of peer reviewers, with an emphasis on the subconscious, or implicit, biases of reviewers.

Ginther et al. (Ginther et al., 2011) did explore the possible impact of some mediating variables (see the Multivariate Regression section of the Supplementary Materials) - in essence, the authors used a statistical procedure to measure the potential contribution of variables associated with PI race to grant funding success. The formal goal was to determine how much of the variance in grant success could be attributed to $\mathrm{PI}$ race as opposed to other contributing factors such as $\mathrm{NIH}$ funding rank of the Pl's Ph.D. granting institution, the field of study, prior success of the applicant, the name or perceived prestige of the University the PI works for, the prior study section experience of the applicant, etc. In short, even when accounting for the effects of factors that might be reasonably expected to (or have been proven to) alter grant success, applications submitted with African-American/Black PIs were still at a significant disadvantage when compared to those applications with white PIs.

A follow-up study by the same group (Ginther et al., 2018) examined the effects of an applicant Pl's publication history on racial funding disparities. Differences in the numbers of publications, the number of academic citations of those publications and the "impact factor" of the journals in which they were published were used in additional statistical models. Numerous other factors were examined as well, but the bottom line is that only $25 \%$ of the funding gap was explained by supposedly objective measures related to scientific productivity. Beyond this problem, the examination of these supposedly objective markers of career success is a flawed approach for several reasons. First and foremost, a scientist's publication history is impacted at every level by prior funding success - if prior grant applications by African-American/Black scientists were less likely to be funded, this would not be separable from publication metrics in this analysis. Funding dictates the number of papers produced per unit time and often dictates the impact factor of the journals in which they are published. Recruitment of trainees and establishment of collaborations increase the number and impact of publications generated by a PI, and both of these require grant funding. In short, every "objective" measurement of scientific output is related to prior funding. Second, and perhaps more importantly, the NIH does not award grants on the basis of such quantitative review of publication metrics of success. Although there is an Investigator criterion section in grant review, and although this criterion is permitted to be used in any weighting with four other categories (Significance, Innovation, Approach and Environment), there are many more elements of the merit of the Investigators that can be considered beyond publication metrics. In our experience, the specificity of the scientific expertise of the PI and other Investigators is the more critical factor, at least in the explicit (written and in-person discussion) portion of the peer review process. More importantly, data from the $\mathrm{NIH}$ show that overall impact scores (the primary outcome of the initial peer review process) are most strongly correlated with Approach and Significance, somewhat less so with Innovation, and are correlated most weakly with Investigator and Environment (Berg, 2010; Rockey, 2011). Therefore, the "Investigator" criterion, which is the grant review criterion most closely aligned with publication metrics, is a weak contributor to the final ranking, and therefore likelihood of funding, of grants. This suggests that any relationship of publication measures with grant award success may be a spurious one in which both measures are correlated with other, more important, variables.

A more recent report examining similar grant award outcome measures found that nothing had changed for a sample of applications submitted after the ones in the Ginther dataset as was described by Hoppe and colleagues (Hoppe et al., 2019). This 
new sample included both Type 1 (new project) and Type 2 (competing renewal) R01 applications that were submitted for possible funding in FY2011FY2015. As with the Ginther (Ginther et al., 2011) sample, submitted applications with white PIs enjoyed a 1.7 fold advantage in funding success compared with applications with Black PIs, despite the fact that overall $\mathrm{NIH}$ success had fallen (from $29.3 \%$ to $17.7 \%$ for applications with white PIs; from $17.1 \%$ to $10.7 \%$ for applications with AfricanAmerican PIs) in this interval and despite the fact that a new peer review system for evaluating grants had been put in place. It is important to emphasize another major result from the Hoppe et al. (Hoppe et al., 2019) paper, indeed it was the stated focus of the authors of the report and the focus of most NIH comments on the report after its publication $(\mathrm{NIH}$, 2019). The Hoppe et al. (Hoppe et al., 2019) abstract states that "topic choice alone accounts for over $20 \%$ of the funding gap" between Black and white scientists. That left $\sim 80 \%$ of the funding gap unaccounted for - but to hear NIH tell it, AfricanAmerican/Black scientists simply work on research topics that are more competitive to get funding for, and that explains the lower funding rates $(\mathrm{NIH}$, 2019). The takeaway messaging tends to skip over the admission in Hoppe et al. (Hoppe et al., 2019) that applications from African-American/Black scientists are funded less frequently even when research topic is accounted for. Interestingly Hoppe and colleagues do address the "Matthew effect", i.e., that prior funding success stimulates productivity which then facilitates more grant awards in a feedforward loop, at some length but ultimately does not seem to recognize the essential role that it plays.

There are many more subtle results in these papers that speak to different questions, concerns and proposed explanations. For example, Black PIs are required to, on average, submit a grant more times before it is funded and Black PIs are less likely to revise and resubmit a previously-reviewed R01 grant application (Table S6 in Ginther et al., 2011) another double whammy. Furthermore, variables that track with better impact scores for the full sample, when including grant applications from all races/ethnicities, do not track with better impact scores for Black PIs (Figure S4 in Ginther et al., 2011). Factors that improve success rates such as publishing with co-authors who publish in the upper quartile of their fields and attaining Full Professor rank, still fail to close the Black/white PI gap (Ginther et al., 2018).
An extremely important finding in these papers relates to the fact that NIH ICs do not fund grant applications strictly in the order of the priority voted in the initial peer review study sections. Nearly every application in the best scoring (lowest scores) bins are funded, but the probability of award is gradually reduced as the priority score increases (i.e., gets worse). Hoppe et al. (Hoppe et al., 2019) reported that zero grants with AfricanAmerican/Black PIs were funded with percentile ranges worse than a 34th percentile ranking, whereas approximately 119 grant applications with white PIs were funded with rankings of 35-59 percentile. These numbers are approximate because the exact number of applications in each percentile bin were not provided by Hoppe et al. (Hoppe et al., 2019), see (Drugmonkey, 2020a) for estimation rationale. Remarkably, the 119 applications with white PIs that scored lower than any funded application with a Black PI, is $46.5 \%$ of the number of total funded applications with Black PIs. It is important to note that $\sim 1.5 \%$ of total applications are submitted by Black PIs - this is a problem in and of itself, but it also makes the disparity relatively easy to address by reversing or equalizing disparities in discretionary funding decisions. This approach would not require formal programmatic change - if discretionary funding decisions can be made in a way that favors white PIs over Black PIs by a 119-0 margin, then they can just as easily be made in a more equitable way.

\section{Action Items on Data Transparency from NIH}

The reports from Ginther and from Hoppe show that it is long past time for the NIH to publish relevant review statistics that pertain to race and ethnicity on a regular basis. They do so for success rates based on grant mechanism, type code (new grants versus competing continuations), the sex of the PI and the stage of investigator, using the $\mathrm{NIH}$ RePORTER website portal. The NIH has more recently issued statistics on the per-investigator success over, say, a five-year interval. The Center for Scientific Review (CSR) of the NIH should start to publish race and ethnicity data for each standing study section on at least an annual basis. This should also be accompanied by statistics on reviewer sex, geographic location, career stage and funding status. In order to ensure full transparency and the ability to analyze data over time, longitudinal data reaching back to the creation of specific study sections should be recovered, published and continued to be published with each update. The 
CSR should also publish success rates for applications and applicants to each study section disaggregated by race and ethnicity. Rationales that too few applications are available and would somehow violate "privacy" of applicants should not be tolerated as legitimate excuses. If this is perceived to be a problem, the simple fix would be to obtain consent from those applicants to include their de-identified applications in the dataset. We have tremendous confidence that Black Pls would be happy to contribute to the process of rectifying the finding disparity first identified by the Ginther et al. study in 2011.

\section{Action Items at the level of Federal Grant Review}

This call to action extends most assuredly to the process of grant review at the NIH. As stated by CSR Director Noni Byrnes in a June 12, 2020 blog post (Byrnes, 2020), "since 2019, CSR has initiated a number of efforts to mitigate bias, both at the individual and systemic levels." Since that time, CSR leadership (i.e., CSR Director and Deputy Director) has convened several meetings with scientist stakeholders to receive feedback on their action items and generate ideas for new short- and longterm solutions (for summary of those meetings, see (Kramer et al., 2020).

The CSR action items released in June 2020 are paraphrased below:

1. Development of bias-awareness training modules for reviewers and staff.

2. Decoupling of the science/idea aspects of the review (Significance, Innovation, Approach) from the person-based aspects (Investigator, Environment).

3. Initiation of a multi-stage, partially doubleblinded review process for the Common Fund transformative R01 reviews in fall 2020.

4. Broadening of the pool of reviewers with respect to career-stage, including doubling the number of early-career reviewers serving on our committees, and actively encouraging recruitment of associate and assistant professors. The rationale is that these cohorts are more diverse in both gender and race/ethnicity.

5. Identification and of those who manipulate the peer review process, and initiation of ameliorative action. Those involved in or unfairly benefiting from the tampering are rarely women and are almost never from under-represented minority groups.

These action items come with significant limitations, as outlined below:

Action item \#1: Development of bias-awareness training modules for reviewers and staff.

This action item may help and has been in process for some time, but frankly, it will not fix the problems being discussed here. There are already academic works appearing that show that anti-bias training does not result in changes to biased behavior (Chang et al., 2019; Glasman and Albarracin, 2006; Kaste, 2020) and more general reviews emphasize a profound lack of empirical support for success (Paluck and Green, 2009). The $\mathrm{NIH}$ should not rely (solely) on this strategy to create substantive change.

Action Items \#2 and 3: Decoupling of the scientific sections from person-based sections of the applications and/or anonymizing applications.

This action item is also unlikely to fix the issues being discussed here. In a recent study conducted by CSR (and described in the forums summarized in (Kramer et al., 2020)) applications were anonymized according to $\mathrm{PI}$ name, but redaction was only partially successful (i.e., some reviewers figured out which applications came from which PIs), and application scores for AfricanAmerican/Black scientists did not improve. The results of this study, which examined 1200 applications, is likely to persist in the "real world" if the strategy is implemented at a CSR-wide scale. Why will this be the case? Because PIs work on incredibly niche areas of science that are easily recognizable according to preliminary data and study design, and PIs frequently cite their own work in grants to build the case for the potential impact of the research proposal under consideration

These proposals do not seem to understand the difficulty of anonymizing grant review and the dangers of variable and undetected breakdown in the anonymization. A deeply flawed study, funded by the NIH in the wake of Ginther et al (Ginther et al., 2011), attempted to detect implicit bias by changing the PI names of applications and having them reviewed by different reviewers in parallel (Forscher et al., 2019). The authors concluded that this proved the absence of implicit bias. The major flaw was that they did not systematically determine if their 
deception had been detected, nor account for how this explicit knowledge may have influenced review. Indeed, the study did indicate that some reviewers caught on to their purpose. This is undoubtedly due to their selection of "white" names such as Greg Murphy and Anne Kelly to be contrasted with "black" names such as Darnell Washington and Latonya Jackson. It is impossible to study implicit bias when the subject reviewers have been cued to the true purpose of the study.

Action Item \#4: Broadening of the pool of reviewers with respect to career-stage.

This action item has some hope of addressing the grant success bias, in that it aims to change something that would potentially have an impact - that is, the composition of reviewers on study section. One of us (MAT) attempted to point out some time ago, albeit tepidly, that an ongoing rush to purge NIH study sections of assistant professors at that time was unwise (Taffe, 2006). Depending on whether one is discussing standing study section members or including ad hoc panel members, only about $2-4 \%$ of CSR reviewers are African-American/Black (e.g., see Table S10 in Hoppe et al., 2019). Importantly, many CSRprocessed federal grant applications are reviewed in special emphasis panels (SEP; i.e., not in standing study sections that have been included in prior analyses) for which the race composition is currently unreported. It is encouraging that CSR has stated publicly that they will turn their attention next to examining how SEPs are composed and what the impact of that might be on grants submitted with PIs from different races (Kramer et al., 2020). We expect them to follow through on this promise and it will be important for the extramural community to hold them to it. It is critical to note the vicious cycle whereby underrepresentation of African-American/Black reviewers on study section likely contributes to lower funding rates of grant applications with Black PIs and lower funding rates of grant applications with Black PIs directly leads to underrepresentation of AfricanAmerican/Black reviewers on study section. This is because reviewers are generally drawn from the pool of those who have already served as a PI on a $\mathrm{NIH}$ grant. The cyclical nature of this disparity needs to be acknowledged and addressed with direct intervention.

In general, CSR instructs scientific review officers (SROs; the individuals that assemble study section rosters and assign grant application to reviewers) that, in constituting study sections, "there must be diversity with respect to the geographic distribution, gender, race, and ethnicity of the membership" (CSR, 2020). There is no available published target as to what this diversity means. The context implies that this instruction only refers to chartered members of a standing study section, but it should be interpreted to apply generally to the membership of a chartered review group, i.e., including ad hoc reviewers. As mentioned above, by most available estimates, $2-4 \%$ of grant reviewers at CSR are African-American; this falls far below the $14 \%$ of U.S. citizens that identified themselves as African-American, or mixed race including AfricanAmerican, on the 2010 census. Furthermore, because most standing study section meetings have between 15 and 30 reviewers on the roster, and SEPs are often much smaller (5-10 reviewers), one could reasonably expect for there to be between 0 and 1 African-American/Black reviewers on many, if not most, grant review panels.

Because the NIH is a taxpayer-funded entity tasked with improving the health of all Americans, it is our view that the targets for diversity should at least reflect the diversity of the nation. To that end, the target for study section composition should seemingly reflect those national race numbers, which would mean that approximately $14 \%$ of federal grant reviewers should be AfricanAmerican/Black, according 2010 census data. This approach is at odds with what has been publicly stated by CSR Director Noni Byrnes as the target number of African-American/Black reviewers on study section, which she has stated should reflect the proportion of African-American/Black scientists in the field. It is unclear on what rationale this is based but what is very clear is that it is a recipe for continuing the disparities of the status quo. If Black scientists cannot succeed within their fields, the numbers of Black scientists will never increase, and therefore the representation of Black scientists on review panels will never increase. It is our view that, to avoid circular logic that will not actually improve study section composition, the best approach is direct intervention and the ideal target percentage of African-American/Black reviewers on study section should reflect U.S. population demographics. Furthermore, it is our view than any argument that this approach would "overburden" AfricanAmerican/Black scientists in the field (i.e., by having a higher percentage of African-American/Black scientists on study section than there are in the field) is far outweighed by the potential systemic benefits 
of this approach. Of course, since study section service is voluntary it is unnecessarily patronizing to decide what is in the interest of any investigator, instead of letting them choose whether to accept an opportunity for study section service. Appropriate target numbers notwithstanding, it is critical to note that target numbers for diversity of grant reviewers must be applied not only to standing study sections, but also to ad hoc reviewers (often $30-50 \%$ of a given study section meeting roster) and special emphasis panels (where many grants, including larger P-mechanism and U-mechanism projects, are reviewed).

It is encouraging that CSR wants to address the issue of disparities in study section composition, but it is perplexing that they propose to achieve this by recruiting younger reviewers. They say they will use this strategy because "these cohorts are more diverse in both gender and race/ethnicity." But it is not clear why, if having study section rosters that are more racially balanced is the goal, the policy does not simply instruct SROs to recruit more AfricanAmerican/Black reviewers. It is possible that CSR leadership believes there are not Black scientists with the expertise available to serve on study sections while maintaining fair expert review for the applicants - we really hope this is not their position. The other possibility is that CSR leadership genuinely believes they can achieve diversity in grant review, and that they believe the best approach is to recruit young scientists to serve on study section, as explicitly stated in their action items "to mitigate bias" by "broadening the pool of reviewers with respect to career-stage". In this scenario, they are essentially admitting that they believe that Black scientists with appropriate expertise to serve on study sections is available (albeit in the younger cohorts of Assistant/Associate Professors), in which case it is not clear why they do not simply state they will recruit more Black reviewers. One could imagine this taking on several forms, for example, through the use of a program that is similar to, but not folded into, and therefore diluted by, the Early Career Reviewer program (which, interestingly, started as a program intended to racial inequities in peer review, but was never implemented in this way). No matter what form it takes, such an initiative or program would almost undoubtedly have positive effects on the funding rates for Black applicants. This might be a direct effect of reducing bias and increasing fairness in study section due to more racial balance, but perhaps more importantly it would give a greater number of Black scientists much-needed insight into the peer review process, thereby increasing the likelihood that their own applications will be competitive for funding. Ask any funded scientist what the single most important factor was in getting funded - many of them will say this factor was the opportunity to review grants written by others and see the inner mechanics of study section.

Action Item \#5: Exclusion of people that tamper with the integrity of the review process.

This point sounds admirable, and has been of recent concern $\mathrm{NIH}$-wide (Lauer and Amero, 2019), but one wonders why this hasn't always been the case. Also, it is not clear where there is a direct connection between this action item and improving the rankings of federal grant applications with Black PIs. It would be of interest for future communications from the CSR to address how prior violations of the integrity of peer review, to which they have referred only obliquely, may have contributed to a bias in the success rates for applications with Black PIs since they have raised this issue in this context.

\section{Action Items at the level of NIH Institutes and Centers}

While the voted scores from the study section process are a main driver for the selection of grants for funding, this is just the beginning of a process that is ultimately only advisory to the Director of an NIH Institute/Center (IC). The IC Director makes the final determination of which grants are to be funded and not funded. The ICs differ widely in their processes and strategies, and a given IC may change its approach over time. Some ICs do fund grants primarily in the order that they are ranked by peer review (a percentiling process is included to attempt to account for differences in scoring calibration across study sections - this works unevenly at best) in an approach termed a "hard payline", where payline refers to the score (or percentile; lower is better) below which almost every application is funded, and above which almost no applications are funded. Other ICs have a "softer payline," an approach where above the line, grants have some decreasing probability of funding as scores fall farther and farther away from the cutoff. The distance between the payline and the almost inevitably unfundable score differs from one IC to another and may vary within a single IC from year to year. Furthermore, the precise shape of the probability function may also vary according to various factors. The reasons for selecting one grant 
for funding over another within a given percentile score rank (or for choosing to fund a grant with a score that is worse than some unfunded grants) are varied (Kienholz and Berg, 2013) and are often referred to as programmatic priorities.

The role of Program (here collectively the process of recommending grants for funding outside of the "definitely fund" zone by individual Program Officers, their Branch and Division processes, the Advisory Council meeting and ultimately the Director decision) in determining which grants are funded and which are not can be significant. In Hoppe et al. (Hoppe et al., 2019), Table 1 shows the percentage of the total funded applications from Black and white PIs according to the percentile rank emerging from the initial peer review process, binned into five percentile ranges $(0-4 \%$ ile is the best, $85-89 \%$ ile is the worst). Almost all applications in the best two bins (0-9\%ile) from African-American/Black and white PIs were funded. Table 1 of Hoppe et al., 2019 also confirms in this sample that the chances of an application being funded decreases monotonically with percentile bin, i.e., the further it occurs away from the very best scores, the less likely it is to be funded. Strikingly, below the $34^{\text {th }}$ percentile, there were zero applications funded with AfricanAmerican/Black PIs. In contrast, some (i.e., more than zero) applications with white PIs were funded all the way to the bin including the $59^{\text {th }}$ percentile. In other words, applications with white PIs were selected for funding even though they had far worse scores than unfunded applications from AfricanAmerican/Black PIs.

The data in Table 1 of Hoppe et al. (Hoppe et al., 2019), as presented, do not give sufficient information as to know how many applications are represented in the percentile bins. However, the Supplement Table S1 shows that there were 103,620 applications submitted with white PIs in this sample. If the above mentioned 35-59th percentile range represents $\sim 25 \%$ of the distribution ( 5 bins, $5 \%$ ile points per bin), then this would represent approximately 25,905 applications, or 5,181 in each bin. Multiplying each of the bin success rates from the Table 1 against this bin estimate produces approximately 119 applications with white PIs that were funded from the $34^{\text {th }}$ to $59^{\text {th }}$ percentile - in this range, zero applications with Black PIs were funded. The Hoppe et al. (Hoppe et al., 2019) conclusion was that since their statistical procedure failed to confirm a significant difference, Program decisionmaking with respect to funding awards out of order of review was not contributing to racial disparities in funding. This would appear to be a clear case in which where the inferential statistical conclusion of "no difference" completely fails to address the quantitative difference and the meaningful impact.

Repairing this Program exception pay (the term for funding grants with worse scores than the nominal payline) disparity would appear to be numerically quite simple, as previously discussed (Drugmonkey, 2020a, b). The 119 applications with white PIs that were funded in the $34^{\text {th }}$ to $59^{\text {th }}$ percentile is almost half $(46.5 \%)$ of the total number of applications with African-American/Black PIs that were funded. If all of those 119 discretionary funding decisions had gone to applications with AfricanAmerican/Black PIs instead of applications with white PIs, the funding rate of applications with African-American/Black PIs would rise from $10.7 \%$ to $15.6 \%$, and the funding rate for applications with white PIs would decline from $17.7 \%$ to $17.56 \%$ ! This could even be accomplished by funding some of the many unfunded applications with AfricanAmerican/Black PIs that were not funded at ranks better than the $34^{\text {th }}$ percentile, thereby improving the "merit" of the funded population of grants.

Another potential approach to fixing this problem would be adaptation of a program that was long ago put in place to increase funding rates for applications with more junior PIs, which were also historically at a disadvantage in terms of federal grant funding rates relative to more senior more established PIs. In fact, there have been many $\mathrm{NIH}$ initiatives attempted, starting at least as early as 1977 (NIH, 2020). In the case of funding bias against applications with new, untried PIs, the factors contributing to the funding disparity are many, including but not limited to the fact that junior PIs have fewer resources, junior PIs often have less preliminary data supporting their hypotheses, and junior PIs have not yet been on study section reviewing application for scientific merit - and these factors likely interact with each other. In 2007, the $\mathrm{NIH}$ launched yet another attempt to fix a perceived bias against younger investigators (Kaiser, 2008) by dissociating them from the pool of all applications with PIs who had never held major NIH funding (termed "New Investigators"). NIH had belatedly realized that which was obvious to most reviewers after only a single study section, i.e., that the most competitive "New Investigator" applications were those with highly experienced PIs who simply happened to have never obtained funding from the 
NIH. As such, special funding policies addressing these New Investigators failed to improve the fate of applications with genuinely younger/newer investigators - these latter individuals were termed Early Stage Investigators, or ESIs, from 2007 onward. A number of policies were then put in place to enhance the funding of applications with ESI PIs, including a relaxed payline that applied only to those applications. It is critical to note that the NIH did not engage in any investigations into the "real source" of the ESI funding disparity, did not propose anti-bias training of reviewers and did not propose that improvements to the training pipeline would somehow solve the problem many years in the future. They simply declared the funding disparity an inappropriate bias in the review process and put in place a set of top-down quota-based affirmative action procedures to redress the funding disparity.

In a parallel, but unassociated program, CSR created the Early Career Reviewer (ECR) program which was designed to give junior PIs the opportunity to sit on study section earlier in their career. This is a program that was perceived by many, within CSR and reviewers alike, as likely to improve the likelihood of funding success of subsequent grant submissions from those junior PIs. It was less clear whether there was general agreement that this ECR program should give junior PIs a critical voice (equal to the voice of more senior reviewers) in the assessment of grant applications. Indeed, the program was originally capped at placing a single ECR on each study section panel (this cap was recently increased to two, if the SRO chooses), and it is customary that ECR reviewers are assigned 1-2 grants and only as tertiary reviewers. These policies suggest that the CSR did not intend ECR reviewers to have much influence on grant scores or funding outcome - this approach should not be replicated in addressing racial disparities in study section composition.

The ESI and ECR programs show that there is absolutely no reason that similar types of programs could not be implemented with respect to African-American/Black PIs and other subgroups of underrepresented and disenfranchised PIs applying for federal grant funding. Furthermore, there is absolutely no reason this type of approach could not and should not be done immediately.

\section{Conclusion}

It is unacceptable that $\mathrm{NIH}$ grant funding disparities based on the race of the $\mathrm{PI}$ continue to persist in the current system. It is unacceptable that the funding gaps reported in Ginther et al. (Ginther et al., 2011) persisted in Hoppe et al. (Hoppe et al., 2019), even though the year ranges examined in the two reports were a decade apart (with the years examined in Hoppe et al. being the five years after publication of the Ginther et al. study). It is unacceptable, nine years past the original report, that we must await the occasional publication of findings from targeted studies to see if funding rates for grant applications with African-American/Black $\mathrm{PIs}$, and other PIs of color, continue to suffer from a bias. It is unacceptable that programs are implemented on an $\mathrm{NIH}$-wide or CSR-wide scale to address some disparities (e.g., career stage) in federal grant funding rates, but not to address disparities related to race - this suggests that addressing racial disparities in federal grant funding is not an impossible task and that the failure to do so is a choice by NIH leadership. It is unacceptable that presentations of funding disparity data often appear sculpted to present an argument that excuses the $\mathrm{NIH}$ and blames African-American/Black PIs (e.g., for not working on the "correct" research topics). Finally, it is unacceptable that health conditions and topics of interest to Black citizens are systematically overlooked for research funding. It is our duty as biomedical research scientists being affected by (and/or benefiting from) this systemically racist structure to demand better. The taxpayer-funded $\mathrm{NIH}$ must acknowledge that systemic and structural racism exists within the Institutes and must create a plan with actionable items that will have a real and lasting impact on the racial disparities discussed in this article. 


\section{Acknowledgments}

This work was not supported by any funding bodies.

Both authors have served as PIs (as well as coinvestigators) on numerous $\mathrm{NIH}$-funded research grants and were awarded NIH fellowship/traineeship funding prior to obtaining independent professorial appointments. Dr. Taffe served a 4-year appointed term on NIH study section (2005-2009) and has reviewed occasionally as an ad hoc reviewer from that time until the present on panels variously reviewing research grants, centers and training mechanisms. Dr. Gilpin has served for the last 4 years as a standing member on NIH study section and has participated as an ad hoc reviewer on various other panels reviewing research grants, centers, consortia, and training fellowships. Dr. Gilpin founded and oversees a Google Slack forum that focuses on "Racial Equity in Science." Dr. Taffe has discussed numerous themes and statistics presented herein writing under the pseudonym Drugmonkey, in the eponymous blog (currently available at https: drugmonkey.scientopia.org) and the associated Twitter account @drugmonkeyblog. Dr. Taffe also discusses some of these issues under the Twitter account @effatma. Dr. Gilpin discusses these issues under the Twitter account @The_Gilp.

\section{Conflict of interest}

Dr. Gilpin owns shares in Glauser Life Sciences, Inc., a company with interest in developing therapeutics for mental health disorders. There is no direct link between those interests and the work contained herein. Dr. Taffe has no conflicts of interest to report.

\section{References Cited}

Berg, J., 2010. Scoring Analysis: 1-Year Comparison.

https://loop.nigms.nih.gov/2010/08/scoringanalysis-1-year-comparison/. (Accessed Nov 19 2020).

Byrnes, N., 2020. Race \& Peer Review. https://www.csr.nih.gov/reviewmatters/2020/ 06/12/race-peer-review/. (Accessed Jul 15 2020).

Chang, E.H., Milkman, K.L., Gromet, D.M., Rebele, R.W., Massey, C., Duckworth, A.L., Grant, A.M., 2019. The mixed effects of online diversity training. Proc Natl Acad Sci U S A 116(16), 7778-7783.
Corbyn, Z., 2011. Black applicants less likely to win NIH grants. Nature 10.1038/news.2011.485

CSR, 2020. How Scientists Are Selected to Be Members of a Chartered Review Group. https://public.csr.nih.gov/ForReviewers/Bec omeAReviewer/CharteredReviewers.

(Accessed Jul 6 2020).

Drugmonkey, 2020a. "Merit" and the NIH disparity of grant award to Black PIs. https://drugmonkey.scientopia.org/2020/06/ 10/merit-and-the-nih-disparity-of-grantaward-to-black-pis/. (Accessed Jun 10.

Drugmonkey, 2020b. On adjusting the funding disparity in NIH grant awards. https://drugmonkey.scientopia.org/2020/06/ 16/on-adjusting-the-funding-disparity-in-nihgrant-awards/. (Accessed Nov 19 2020).

Dzirasa, K., 2020. For Black Scientists, the Sorrow Is Also Personal. Cell 182(2), 263-264.

Forscher, P.S., Cox, W.T.L., Brauer, M., Devine, P.G., 2019. Little race or gender bias in an experiment of initial review of NIH R01 grant proposals. Nat Hum Behav 3(3), 257-264.

Ginther, D.K., Basner, J., Jensen, U., Schnell, J., Kington, R., Schaffer, W.T., 2018. Publications as predictors of racial and ethnic differences in NIH research awards. PLoS One 13(11), e0205929.

Ginther, D.K., Schaffer, W.T., Schnell, J., Masimore, B., Liu, F., Haak, L.L., Kington, R., 2011. Race, ethnicity, and NIH research awards. Science 333(6045), 1015-1019.

Glasman, L.R., Albarracin, D., 2006. Forming attitudes that predict future behavior: a metaanalysis of the attitude-behavior relation. Psychol Bull 132(5), 778-822.

Hart, C.L., 2020. Exaggerating Harmful Drug Effects on the Brain Is Killing Black People. Neuron 107(2), 215-218.

Hill, E., Tiefenthaler, A., Triebert, C., Jordan, D., Willis, H., Stein, R., 2020, How George Floyd Was Killed in Police Custody. New York Times. The New York Times Company. https://www.nytimes.com/2020/05/31/us/geo rge-floyd-investigation.html

Hoppe, T.A., Litovitz, A., Willis, K.A., Meseroll, R.A., Perkins, M.J., Hutchins, B.I., Davis, A.F., Lauer, M.S., Valantine, H.A., Anderson, J.M., Santangelo, G.M., 2019. Topic choice contributes to the lower rate of $\mathrm{NIH}$ awards to African-American/black scientists. Sci Adv 5(10), eaaw7238. 
Kaiser, J., 2008. Zerhouni's Parting Message: Make Room for Young Scientists. Science 322(5903), 834-835.

Kaste, M., 2020, NYPD Study: Implicit Bias Training Changes Minds, Not Necessarily Behavior. NPR. National Public Radio. https://www.npr.org/2020/09/10/909380525/ nypd-study-implicit-bias-training-changesminds-not-necessarily-behavior

Kienholz, M., Berg, J.M., 2013. How the NIH Can Help You Get Funded: An Insider's Guide to Grant Strategy 1ed. Oxford University Press.

Kramer, K., Jain, A., Fleming, L., 2020. Content Analysis: Forums on Racial Disparities in Peer Review and More, in: Review, C.f.S. (Ed.). National Institutes of Health. https://public.csr.nih.gov/sites/default/files/2 020-

09/CSR_July_2020_Racial_Disparities_in_ Funding_comment_summary.pdf

Lauer, M., Amero, S., 2019. Breaches of Peer Review Integrity. https://nexus.od.nih.gov/all/2019/06/25/brea ches-of-peer-review-integrityl. $\quad$ (Accessed Nov 23 2020).

$\mathrm{NIH}$, 2019. Research topic contributes to persistent gap in $\mathrm{NIH}$ research grants to black scientists. https://www.nih.gov/newsevents/news-releases/research-topiccontributes-persistent-gap-nih-researchgrants-black-scientists.

NIH, 2020. A History of New and Early Stage Investigator Policies and Data. https://grants.nih.gov/policy/earlyinvestigators/history.htm. (Accessed Jul 23 2020).

Odekunle, E.A., 2020. Dismantling systemic racism in science. Science 369(6505), 780-781.

Paluck, E.L., Green, D.P., 2009. Prejudice reduction: what works? A review and assessment of research and practice. Annu Rev Psychol 60, 339-367.

Pickett, C., 2018. Examining the distribution of K99/R00 awards by race. http://rescuingbiomedicalresearch.org/blog/ examining-distribution-k99r00-awards-race/. (Accessed 11/23 2020).

Rockey, S., 2011. Correlation Between Overall Impact Scores and Criterion Scores. https://nexus.od.nih.gov/all/2011/03/08/over all-impact-and-criterion-scores/. (Accessed Nov 19 2020).

Taffe, M.A., 2006. Peer review and new investigators. Science 311(5762), 775. 